\title{
Similarities and differences between asthma health care professional and patient views regarding medication adherence
}

\author{
Sandra Peláez $\mathrm{PhD}^{1,2}$, Simon L Bacon PhD²,3,4, Mark W Aulls PhD ${ }^{1}$, Guillaume Lacoste $\mathrm{BSc}^{3}$, Kim L Lavoie PhD ${ }^{2,3,5}$
}

\begin{abstract}
S Peláez, SL Bacon, MW Aulls, G Lacoste, KL Lavoie. Similarities and differences between asthma health care professional and patient views regarding medication adherence. Can Respir J 2014;21(4):221. 226.
\end{abstract}

BACKGROUND: The recent literature has reported disparate views between patients and health care professionals regarding the roles of various factors affecting medication adherence.

OBJECTIVE: To examine the perspectives of asthma patients, physicians and allied health professionals regarding adherence to asthma medication. METHODOLOGY: A qualitative, multiple, collective case study design with six focus-group interviews including 38 participants (13 asthma patients, 13 pulmonologist physicians and 12 allied health professionals involved in treating asthma patients) was conducted.

RESULTS: Patients, physicians and allied health professionals understood adherence to be an active process. In addition, all participants believed they had a role in treatment adherence, and agreed that the cost of medication was high and that access to the health care system was restricted. Major disagreements regarding patient-related barriers to medication adherence were identified among the groups. For example, all groups referred to side effects; however, while patients expressed their legitimate concerns, health care professionals believed that patients' opinions of medication side effects were based on inadequate perceptions.

CONCLUSION: Differences regarding medication adherence and barriers to adherence among the groups examined in the present study will provide insight into how disagreements may be translated to overcome barriers to optimal asthma adherence. Furthermore, when designing an intervention to enhance medication adherence, it is important to acknowledge that perceptual gaps exist and must be addressed.

Key Words: Adherence; Asthma; Focus groups; Medication

\author{
Les similarités et les différences entre les points de \\ vue des professionnels de la santé qui soignent \\ l'asthme et ceux des patients au sujet de l'adhésion \\ aux médicaments
}

\begin{abstract}
HISTORIQUE : Les publications récentes font état de points de vue disparates entre les patients et les professionnels de la santé au sujet du rôle des différents facteurs qui influent sur l'adhésion aux médicaments.

OBJECTIF : Examiner les points de vue des patients atteints d'asthme, des médecins et des professionnels paramédicaux au sujet de l'adhésion aux médicaments contre l'asthme.

MÉTHODOLOGIE : Les chercheurs ont mené une étude de cas collective, multiple et qualitative comportant six entrevues de groupes de travail comptant 38 participants (13 patients atteints d'asthme, 13 pneumologues et 12 professionnels paramédicaux).

RÉSULTATS : Les patients, les médecins et les professionnels paramédicaux ont compris que l'adhésion est un processus actif. En outre, tous les participants croyaient avoir un rôle à jouer dans l'adhésion au traitement et ont convenu que le coût des médicaments était élevé et que l'accès au système de santé était restreint. Les chercheurs ont relevé les principales mésententes au sujet des obstacles à l'adhésion des patients aux médicaments entre les groupes. Par exemple, tous les groupes ont parlé des effets secondaires, mais bien que les patients aient exprimé leurs inquiétudes légitimes, les professionnels de la santé trouvaient que l'avis des patients au sujet des effets secondaires se fondait sur des perceptions inadéquates.

CONCLUSION : Les différences relatives à l'adhésion aux médicaments et aux obstacles à cette adhésion entre les groupes examinés dans la présente étude donneront un aperçu sur la manière d'interpréter les mésententes pour vaincre les obstacles à l'adhésion optimale aux médicaments. De plus, lors de la conception d'une intervention pour améliorer l'adhésion aux médicaments, il est important de convenir de l'existence de lacunes conceptuelles, qu'il faut corriger.
\end{abstract}

and/or beliefs about the disease and/or its treatment influence disease management behaviours and subsequent outcomes.

The purpose of the present study was to explore and compare patient, physician and allied health professional perceptions of what is meant by 'adherence to asthma treatment' and 'barriers to medication adherence'. Information from the present study was used as a part of the intervention development process in the Motivational Intervention for Asthma Control Trial (MI-ACT), which was designed to test the use of motivational interviewing techniques $(17,18)$ to improve adherence to controller medication among nonadherent, poorly controlled asthmatic patients (ClinicalTrials.gov Identifier: NCT01132430).

One potential barrier is the relationship between patients' perception of their need for medication and their actual medication intake. For example, older patients' concerns regarding the potential negative consequences of taking prescribed medication and beliefs about its necessity were associated with intentional medication nonadherence (16). Thus, patients who reported high levels of concern about medication would often not take it, whereas intentionally medication-nonadherent patients would consider the pros and cons of taking medication before actually taking it. Therefore, it appears that an individual's perceptions

\begin{abstract}
Study design
METHODS

A qualitative, multiple and collective case study (19-21) was conducted with asthma patients, asthma physicians and allied health professionals involved in the treatment of asthma patients.
\end{abstract}

${ }^{1}$ Education and Counselling Psychology, McGill University; ${ }^{2}$ Research Centre, Montreal Heart Institute; ${ }^{3}$ Montreal Behavioural Medicine Centre, Hôpital du Sacré-Coeur de Montréal; ${ }^{4}$ Department of Exercise Science, Concordia University; ${ }^{5}$ Department of Psychology, Université du Québec à Montréal, Montreal, Quebec

Correspondence: Dr Sandra Peláez, Department of Educational and Counselling Psychology, McGill University, 3700 McTavish Street, Montreal, Quebec H3A 1Y2. Telephone 514-398-4969, fax 514-398-4679, e-mail sandra.pelaez@mail.mcgill.ca 


\section{Participants}

The study was approved by the Research Ethics Board of the Hôpital du Sacré-Cour de Montreal, Montreal, Quebec. Thirty-eight participants (13 patients [one group of six and one of seven], 13 physicians [one group of eight and one of five] and 12 allied health professionals [two groups of six]) from a single university-affiliated general hospital were purposefully sampled. All physicians were pulmonologists and all allied health professionals worked in the pulmonology department (respiratory technicians, pharmacists, nurses or asthma educators). Patients were included if they were an adult, had a diagnosis of asthma, spoke French and had a prescription for inhaled corticosteroids for at least 12 months. Demographic information regarding the patients is summarized in Appendix A. Of note, all patients completed the Asthma Control Questionnaire and reported, as measured by this instrument, adequate levels of adherence $(>80 \%)$.

\section{Data collection}

Six focus-group interviews (22) were conducted in 2009 over a threemonth period. To explore participant understanding of and barriers to medication adherence, a semistructured, in-depth interview (23) was designed (24) (Appendix B). Focus-group procedures were piloted to ensure clarity and interpretability before beginning data collection.

The moderator (GL), who guided the interview, and the participant observer (SP), who took notes and occasionally participated, were present at all focus groups. A professional stenographer, external to the research team, attended the focus groups and transcribed the interviews verbatim. Each focus group began with signing of informed consent and an overview of general procedures and rules. Focus group duration was between $90 \mathrm{~min}$ and $120 \mathrm{~min}$. At the end of each meeting, the participants' ideas were summarized and participants confirmed and/or qualified the summary. Participants were not reimbursed but refreshments were provided.

\section{Data analysis}

Transcripts were coded following the basic principles of inductive coding (25) consisting of labelling identified meaning units, organizing data into emerging categories based on their attributes and identifying patterns among coded categories. This type of coding relies on constant comparison of instances (ie, categories) for relations, commonalities and differences (26). Both in vivo codes (ie, participants' words) and constructed codes (ie, terms created by the researcher when making inferences) were used. Preliminary analysis was presented to the rest of the research team, who provided feedback that was used to develop the final coding (27)

A case-specific and cross-case analysis was performed (20). Identified patterns were used to develop case-specific summaries, whereas cross-case analysis was performed by comparing and contrasting data among the groups.

\section{RESULTS}

Perceptions of what is meant by 'adherence to asthma treatment', who is 'responsible for medication adherence' and what are the 'barriers to medication adherence' are presented according to participant group separately, followed by comparisons among participants' opinions. For confidentiality and identification purposes, an acronym (PT for patients, $\mathrm{PH}$ for physicians and $\mathrm{AH}$ for allied health professional) was assigned in additon to a unique number for each participant.

\section{Emergent categories according to participant group}

Patients: Understanding of and responsibility for adherence: Patients described adherence as representing three distinct behaviours. First, the patients referred to adhering to components of asthma treatment other than medication, especially quitting smoking and controlling environmental triggers. PT-04 explained:

We don't have to assume that the drug is going to do all the work. The medication contributes, that's true, but the human being is responsible as well and that entails respecting all the other recommendations suggested by physicians.
Second, patients discussed being actively involved in their treatment, meaning that prescribed medications are dependent on standardized recommendations and adjustments are needed to respond to specific needs. PT-04 said:

When I know that I am going to do more physical activity than what I am used to, I take the meds just for prevention.

Third, patients made reference to taking the medication exactly as prescribed. PT-02 explained:

For me, it's very important to take the medication, so I do the

fillings and I take it exactly as prescribed.

Patients perceived themselves as being responsible for medication adherence. PT-09 said:

For me, there are different levels of responsibility. That of the diagnosis and prescription, ok, it's the physician's. But once I have the prescription in my pocket or at the drug store, it's my own responsibility. The adherence... that belongs to me!

PT-07 added that patients were responsible for being honest with their physician about any issues related to medication:

Another level of responsibility has to do with telling the physician the truth. We have to respect the prescription, we have to respect us, and we have to respect the physician.

Perceived barriers to medication adherence: Medication-related barriers. Some patients described the aerosols and powder inhalers as medication not being user-friendly because it is difficult to know whether it is being used properly (eg, "Have you taken or inhaled the full dose, or not? You never know!" [PT-09]) and "You have to rinse your mouth out after each use" (PT-13). Patients discussed the high cost of the medication. PT-03 said: "It's almost a mortgage!" and PT-06 explained he was forced to ration his medication to reduce expenses:

My physician told me to take my medication in the mornings and in the evenings, but I take it every two days because that's a lot of money!"

Patient-related barriers: The most common barrier to medication intake identified within this category was patients' attitudes and beliefs about asthma and medication. This included patients' denial or inadequate perception of the disease (eg, not recognizing asthma as a chronic inflammatory disease requiring daily medication intake). PT-05 explained:

It frequently happens to me that I do not take my inhalers because when I feel ok I say to myself that it's not necessary.

Other patients discussed their hopes of finding a magical cure for the disease. PT-02 mentioned:

I am tired of medication, so I wonder whether it is possible to

find a solution to stop taking it or is it going to be like that forever?

Some patients mentioned that having a poor attitude (eg, lack of motivation) affected adherence; whereas others reported that due to pride, they avoided taking their medication in front of others. PT-05 said:

We do not want others to know we are asthmatics and we have to take the inhalers.

Patients discussed concerns about the side effects of the medication such as: "Red bumps in the throat" (PT-01), "pain in muscles and bones" (PT01), "dizziness" (PT-02), "weight gain" (PT-01), "decreases in hormone levels" (PT-11) and "dry throat and shaking hands" (PT-05).

Difficulty with inserting medication-taking into their daily routine was another barrier. PT-09 alleged: "It's one extra thing you add to your already busy daily routine".

Health system-related barriers: Restricted accessibility to health care, such as "delayed appointments" (PT-02), "unavailability of services" (PT-07) and "waiting lists" (PT-04), hindered medication adherence because they complicated prescription renewals and medical follow-ups. 
Physicians: Understanding of and responsibility for adherence: The physicians' understanding of what is meant by 'adherent to asthma treatment' focused primarily on patients "taking their medication exactly as prescribed" (PH-14). Only one physician discussed the importance of the patient being actively involved in the treatment and autonomy for taking medication as being important for adherence, saying:

...no matter what their pathology is, patients have to be sensitized to the fact that they are the ones who choose to feel better or not. They should not feel obligated by an external situation. I think they should be sensitized to the fact that they have the choice to adhere, or not, to their treatment.

All physicians agreed with PH-09 who reported: "The main person responsible is the physician, it's not fifty-fifty". Physicians assumed the responsibility of prescribing the medication respecting the patients' needs and characteristics, establishing a trust-based relationship and verifying the patient's response to medication.

Perceived barriers to medication adherence: Medication-related barriers. Physicians mentioned the high cost of the medication was a barrier to adherence. PH-11 said:

One thing is when you are rich and healthy, but in general, when you are poor, you're ill, and normally, those who should take more medication are the ones who are at a lower socioeconomic level.

PH-01 noted:

We prescribe expensive medications, and sometimes, we forget that there are patients who do not have partial or total medication insurance coverage.

Physicians agreed that some medications were not user friendly. They described inhalers as efficacious but "more difficult to use as they require two inhalations (as compared to pills that normally require one dose)" (PH-04) and "technical knowledge" (PH-13) to warrant its proper use. Physicians acknowledged that: "Socially, it's better for patients to take pills than inhalers because they can be taken more discreetly" (PH-09).

Patient-related barriers: Physicians referred to the role of patients' attitudes and beliefs. PT-05 said:

Often, these patients do not see themselves as being ill, especially if you treat a 40 -year-old who has always been healthy and has to accept that his health is no longer perfect.

Physicians mentioned that some patients underestimated the importance of experiencing symptoms. PH-01 explained: "Even if we ask them, 'When it's cold, do you cough from time to time?' They answer: 'No, I cough now and then, but it's not a big deal, everyone coughs". Also, physicians argued that patients' "myths and inadequate beliefs" (PH-07) about the nature of their disease (eg, "asthma is psychological rather than physiological" [PH-10]) misled patients concerning how to treat their disease.

Physicians believed the patients' confusion about the relative benefits of controller versus rescue medication affected medication adherence. They explained that: "the benefits of daily medication are not easily understood" (PH-01) compared with rescue medication that "has an immediate effect and thus is better accepted" (PH-11). According to physicians, some patients experienced their condition as a "handicap affecting their self-image" (PH-05) and "eroding their motivation to adhere to the treatment" (PH-08).

Regarding side effects associated with the medication, physicians admitted there were certain objective side effects, but also, some patients had inadequate (or irrational) perceptions, beliefs and fears about medication. As noted by PH-02: "these beliefs are dangerous because patients stop taking their medication to avoid the side effects". $\mathrm{PH}-13$ referred to patients' fears of becoming addicted to medication:

[Patients] perceive the medication depending on their beliefs. For example, they think that if they take the medication when they have no symptoms, they will get used to it, so when they really need it, it won't work. Like the narcotics, you know?
Physicians believed these inadequate perceptions, beliefs and fears stemmed from being poorly educated and informed about the disease. Physicians agreed that neither the Internet nor medication information pamphlets adequately informed patients. $\mathrm{PH}-02$ said:

The internet may be dangerous because there is not always good stuff there... I don't know how many time patients spend in internet, but they end up having irrational fears".

Two social barriers associated with adherence were acknowledged. According to physicians, friends and family may play a negative role by suggesting that asthma is psychological and by pushing them into "natural medicines other than pharmacological medication" (PH-13). PH-12 also observed that "patients who neither speak French, nor English face a linguistic barrier" that interfered with the understanding of their disease and its treatment.

Health system-related barriers: Having a poor patient-physician relationship because of "the rigid attitude of the physician" (PH-10) often resulted in "miscommunication" (PH-13) and caused a breakdown of the therapeutic relationship by hindering the patients' transparency with the physician. Physicians mentioned that restricted accessibility to health care (eg, "Not having a physician who prescribes the medication (or) having to wait for a long time at the drug store" [PH-01]), was another potential barrier affecting medication adherence.

Allied health professionals: Understanding of and responsibility for adherence: Allied health professionals' understanding of what is meant by 'adherent to asthma treatment' revolved around the importance of taking the medication exactly as prescribed "and not only depending on the patient's perception" (AH-11). Allied health professionals agreed that it was crucial to adhere to components of asthma treatment other than medications; however, "this depended on both the patient's budget and social milieu" (AH-03). Finally, being actively involved in treatment, otherwise "knowing how to overcome the problems related to the management of asthma symptoms" (AH-05), was brought up by allied health professionals. Allied health professionals' acknowledged their responsibility for:

Being sure the medication is appropriate, even in relation to other diseases, and asking patients how they are and checking whether they're using the medication correctly (AH-06).

Helping the patient understand why he or she is taking the medication (AH-07), and (3) triangulating between the physician and the patient (AH-12) because sometimes, the patients confide things in us that they don't confide in their doctors (AH-08).

Perceived barriers to medication adherence: Medication-related barriers: The key medication-related barrier was the high cost of the medication. AH-11 mentioned that patients frequently said:

This already costs me $\$ 300 \ldots$ within the inhalers you are proposing me, which one do you think I should take because I won't be able to buy them all until next month.

AH-03, himself an asthma patient, added:

You have rent to pay, you have your debts, your car; you have to dress your kids, feed them, feed yourself. So when your medication comes into your paying line, probably it annoys you to go and get it.

Patient-related barriers: According to allied health professionals, patients' attitudes and beliefs included inadequate perceptions or denial of the disease, as explained by $\mathrm{AH}-12$ :

The asthmatic is frequently young when he is diagnosed and he is not prepared to accept the disease for the rest of his life.

Denial was worse in "patients who did not feel the effects of the medication and the difference between taking it and not taking it" (AH-07). Allied health professionals mentioned that some patients were "against medication and preferred natural medicine" (AH-08).

Allied health professionals, as physicians, referred to patients' poor education, but they discussed it from a more encompassing perspective. AH-12 said: 
TABLE 1

Summary of main ideas that emerged across all groups of participants

\begin{tabular}{|c|c|c|c|}
\hline & Patients & Physicians & Allied health professionals \\
\hline \multirow[t]{3}{*}{$\begin{array}{l}\text { Understanding } \\
\text { of adherence }\end{array}$} & $\begin{array}{l}\text { Adhering to components of asthma treatment } \\
\text { other than medication }\end{array}$ & & $\begin{array}{l}\text { Adhering to components of asthma treatment } \\
\text { other than medication }\end{array}$ \\
\hline & \multicolumn{3}{|c|}{ Being actively involved in the treatment } \\
\hline & \multicolumn{3}{|c|}{ Taking the medication exactly as prescribed } \\
\hline \multirow{3}{*}{$\begin{array}{l}\text { Perceived } \\
\text { responsibility } \\
\text { for adherence }\end{array}$} & Taking the medication & Prescribing the medication & $\begin{array}{l}\text { Verifying medication issues (eg, adequate } \\
\text { prescription) }\end{array}$ \\
\hline & $\begin{array}{l}\text { Respecting the prescription done by the } \\
\text { physician }\end{array}$ & Establishing a trust-based relationship & $\begin{array}{l}\text { Helping the patient understand why he or } \\
\text { she is taking the medication }\end{array}$ \\
\hline & Being honest with the physician & $\begin{array}{l}\text { Verifying the patient's response to prescribed } \\
\text { medication }\end{array}$ & $\begin{array}{l}\text { Triangulating between the patient and the } \\
\text { physician }\end{array}$ \\
\hline \multicolumn{4}{|c|}{ Medication related } \\
\hline \multirow{10}{*}{$\begin{array}{l}\text { Perceived } \\
\text { barriers to } \\
\text { adherence }\end{array}$} & \multicolumn{2}{|c|}{ Medication not user-friendly } & \\
\hline & \multicolumn{3}{|c|}{ High cost of medication } \\
\hline & \multicolumn{3}{|c|}{ Patient related } \\
\hline & $\begin{array}{l}\text { Attitudes and beliefs (denial, inadequate } \\
\text { perception of the disease, hope of a magical } \\
\text { cure, and poor attitude) }\end{array}$ & \multicolumn{2}{|c|}{ Attitudes and beliefs (denial and inadequate perception of the disease and the medication) } \\
\hline & Concerns related to side effects & \multicolumn{2}{|c|}{ Inadequate perception and experience of possible side effects } \\
\hline & $\begin{array}{l}\text { Difficulty in inserting medication-taking into } \\
\text { their daily routine }\end{array}$ & $\begin{array}{l}\text { Poor education and information (in relationship } \\
\text { to the disease) }\end{array}$ & Poor education (low educational level) \\
\hline & & $\begin{array}{l}\text { Social (language limitations and family and } \\
\text { friends) }\end{array}$ & Social (family and friends) \\
\hline & \multicolumn{3}{|c|}{ Health system related } \\
\hline & \multicolumn{3}{|c|}{ Restricted accessibility to health care system } \\
\hline & & \multicolumn{2}{|c|}{ A poor patient-physician relationship } \\
\hline
\end{tabular}

Let's say that the one who adheres to medication is the one that has been educated and takes responsibility for the disease.

Thus, adherence was often poorer in patients with low levels of education who followed the treatment "for the physician, but not for themselves" (AH-08).

They agreed with physicians on two issues. First, that patients' perception of medication side effects were frequently valid, but not always. AH-10 said:

Rarely side effects could not be solved by prescribing the appro-

priate medication.

Second, that friends and family may negatively affect the patient's perception of the disease. AH-10 said:

There are a lot of patients whose partners tell them: It's in your head that you cannot breathe' and it is difficult for the patient to deal with that.

Health system-related barriers: Allied health professionals also viewed restricted accessibility to health care as a barrier to medication adherence. AH-08 said:

It is not only difficult to have a specialist in pulmonology who diagnoses and prescribed medication, but even to find a general practitioner.

They explained that physicians' poor attitude could influence patient's medication adherence. Due to time constraints, some physicians did not take time to discuss medication with their patients; therefore,

If enough information concerning the medication patients are taking is not collected, physicians may prescribed inhalers without considering what the patient is currently using (AH-12).

\section{Comparison of participant opinions}

Similarities and differences emerged across all groups of participants (Table 1). Patients, physicians and allied health professionals understood adherence as entailing medication intake as exactly prescribed and being an active process (eg, regulating medication depending on the activities) and that high medication cost and restricted accessibility to health care were issues.

Although all participants referred to similar patient-related barriers, the position assumed by the health care professionals was different than in patients. For example, they all referred to side effects, but while patients expressed their legitimate concerns, health care professionals discussed patients' inadequate perceptions, highlighting limited general (ie, educational background) and specific (ie, disease related) education as drivers. It could be that patients' medication concerns move them to consider nonmedication components of treatment.

Some viewpoints were shared by two of the three groups. For example, patients and allied health professionals understood adherence in a broader sense (ie, adhering to other components of asthma treatment [eg, exercise]). Patients and physicians perceived some medication delivery devices as not being user friendly. Health care professionals shared perceptions concerning patient-related (patients' attitude and beliefs, and inadequate perception and experience of possible side effects) and health system-related barriers to medication adherence (a poor patient-physician relationship).

Differences across the three groups were also acknowledged. Participants in each group considered themselves as being responsible for medication adherence but on different levels. The fact that all participants assumed different responsibilities associated with their roles could be perceived as providing complementary roles, but also as a perceptual gap between groups, probably caused by a lack of a shared understanding and/or agreement. For example, physicians assumed the responsibility for prescribing medication and expected patients to take the medication in a passive and obedient manner, whereas the patients regarded themselves as being more active in that role.

\section{DISCUSSION}

The present study explored the relationship among three groups of asthma stakeholders' understanding of and barriers to medication adherence. The data indicated that participants' understanding depended on their perspectives. For example, patients reported 
concerns about side effects of medication that health care professionals tended to associate with patients' inadequate perceptions, in other words, barriers to medication adherence 'constructed' by the patient. It is probable that these gaps are important barriers to optimal asthma (and probably chronic disease) management.

The present study had some methodological limitations. All participants were drawn from the same institution, which may have introduced some perceptual biases and/or limit the generalizability of the findings. Data collection relied solely on focus-group interviews, a methodological strategy that has been widely used in similar studies, $(28,29)$ but may raise social desirability issues. The present study also has some notable strengths. It was the first to triangulate a balanced sample of three different groups of asthma stakeholders and to identify specific areas of disagreement that could be the target of intervention. Also, we followed rigorous qualitative methodology guidelines (25) that increased the robustness and validity of the findings.

Future research should explore how to address the perceptual gaps identified and, therefore, contribute to the design of a feasible and evidence-based intervention to enhance asthma medication adherence. For example, to improve their understanding of their patients' perspectives concerning the disease and its treatment, health care professionals should consider adopting a more patient-centred approach to treatment. A patient-centred care approach, considered to be a pivotal aspect of high-quality health care (30), entails the following: the consideration of the patient as a person from a psychosocial perspective; the enhancement of shared decision making around treatment plans and overcoming barriers; and the development of a stronger patient-physician relationship and a therapeutic alliance (31). As noted in previous research, sharing responsibilities and decision making enhances medication adherence in the context of asthma (32). As such, interventions using shared decision making and motivational interviewing/communication (32-34) to increase intrinsic motivation and foster self-efficacy may be promising for the improvement of asthma medication adherence.

FUNDING: This work was supported by an investigator-initiated grant from GlaxoSmithKline (KLL) and New Investigator Awards from the Canadian Institutes of Health Research (CIHR) and the Fonds de la recherce du Quebec - Sante (FRQS) (KLL, SLB), and was presented at the 2012 Young Investigator Forum (YIF) in Montreal, Quebec (SP).

\section{APPENDIX A}

\section{Patient characteristics}

\begin{tabular}{|c|c|c|c|c|c|c|}
\hline Patient & Sex & Age, years & $\begin{array}{l}\text { Asthma Control } \\
\text { Questionnaire (35) } \\
\text { score, mean }\end{array}$ & $\begin{array}{c}\text { Asthma duration, } \\
\text { years }\end{array}$ & Atopy & Inhaled corticosteroids \\
\hline 1 & Male & 53 & 1.14 & 4 & Yes & Fluticasone propionate $250 \mathrm{mg} /$ day \\
\hline 2 & Female & 31 & 0.85 & 31 & Yes & Budesonide and formoterol $800 \mathrm{mg} / \mathrm{day}$ \\
\hline 3 & Female & 62 & 1.14 & 35 & Yes & Fluticasone propionate 2000 mg/day \\
\hline 4 & Female & 61 & 0.85 & 31 & Yes & Fluticasone and salmeterol $500 \mathrm{mg} /$ day \\
\hline 5 & Male & 68 & 0.43 & 35 & No & Fluticasone propionate 500 mg/day \\
\hline 6 & Female & 75 & 1.57 & 75 & Yes & Fluticasone propionate 1000 mg/day \\
\hline 7 & Female & 44 & 0.57 & 44 & Yes & Budesonide and formoterol $800 \mathrm{mg} /$ day \\
\hline 8 & Female & 48 & 1.14 & 3 & Yes & Budesonide and formoterol $800 \mathrm{mg} / \mathrm{day}$ \\
\hline 9 & Female & 64 & 2.43 & 29 & Yes & Budesonide 800 mg/day \\
\hline 10 & Male & 53 & 1.14 & 9 & No & Fluticasone and salmeterol $250 \mathrm{mg} /$ day \\
\hline 11 & Female & 20 & 2.14 & 20 & Yes & Budesonide and formoterol $200 \mathrm{mg} / \mathrm{day}$ \\
\hline 12 & Male & 65 & 0.71 & 65 & Yes & Budesonide and formoterol $400 \mathrm{mg} /$ day \\
\hline 13 & Female & 39 & 2.14 & 7 & No & Budesonide and formoterol $800 \mathrm{mg} /$ day \\
\hline \multicolumn{2}{|c|}{ Mean \pm SD } & $52.54 \pm 15.79$ & $1.25 \pm 0.64$ & $29.84 \pm 22.31$ & & \\
\hline
\end{tabular}

\section{APPENDIX B \\ INTERVIEW GUIDE}

(Adapted to each participant group)

\section{Introduction}

1. How would you define "treatment adherence"?

a. What could we expect from a patient that adheres to his or her treatment?

b. Could you please describe a profile of a patient that perfectly adheres to medication?

2. Who is mainly responsible for the prescribed medication/ medication you have been prescribed?

a.What is your specific responsibility as (patient/paramedic/ physician)?

3. As a patient... How important is for you to take the medication as prescribed?

4. According to you, what does it take to be adherent to treatment?
Barriers to medication adherence

1. From your viewpoint, what are potential complications related to treatment?

2. Why would the patient/you not take the medication as prescribed? Please provide some examples.

3. What makes it difficult to take a medication as prescribed?

4. Are there barriers possible to be overcome? Why?

a. Do you think that there are insurmountable barriers? Which ones and why?

5. Up to what point do you trust that asthma patients take medication as it has been prescribed? 


\section{REFERENCES}

1. Nici L, Raskin J, Rochester CL, et al. Pulmonary rehabilitation: What we know and what we need to know. J Cardiopulmon Rehabil Prev 2009;29:141-51.

2. Global Initiative for Asthma. Global Strategy for Asthma Management and Prevention. 2011 July 2, 2012. Report No.: NIH Publication No 02-3659.

3. Green RH, Brightling CE, Pavord ID, Wardlaw AJ. Management of asthma in adults: Current therapy and future directions. Postgrad Med J 2003;79:259-67.

4. Lemière $\mathrm{C}$, Bai $\mathrm{T}$, Balter $\mathrm{M}$, et al. Adult Asthma Consensus Guidelines Update 2003. Can Respir J 2004;11(Suppl A):9A-33A.

5. Mintz M. Asthma update: Part I. Diagnosis, monitoring, and prevention of disease progression. Am Fam Physician 2004;70:893-8.

6. Chapman KR, Boulet LP, FitzGerald MJ, McIvor RA, Zimmerman S. Patient factors associated with suboptimal asthma control in Canada: Results from the Reality of Asthma Control Study. Am J Respir Crit Care Med 2005;172:A678.

7. Rowe BH, Edmonds ML, Spooner CH, Camargo CA. Evidencebased treatments for acute asthma. Respir Care 2001;46:1380-91.

8. Colice GL. Categorizing asthma severity: An overview of national guidelines. Clin Med Res 2004;2:155-63.

9. Sin DD, Man J, Sharpe H, Gan WQ, Man SF. Pharmacological management to reduce exacerbations in adults with asthma: A systematic review and meta-analysis. JAMA 2004;292:367-76.

10. Krishnan JA, Riekert KA, McCoy JV, et al. Corticosteroid use after hospital discharge among high-risk adults with asthma. Am J Respir Crit Care Med 2004;170:1281-5.

11. Heaney LG, Robinson DS. Severe asthma treatment: Need for characterising patients. Lancet 2005;365:974-6.

12. Cyr MC, Beauchense MF, Lemiere C, Blais L. Comparison of the adherence and persistence to inhaled corticosteroids among adult patients with public and private drug insurance plans. J Popul Ther Clin Pharmacol 2013;20:e26-41.

13. Drotar D, Bonner MS. Influences on adherence to pediatric asthma treatment: A review of correlates and predictors. J Dev Behav Pediatr 2009;30:574-82.

14. Gillisen A. Patient's adherence in asthma. J Physiol Pharmacol 2007;58(Suppl 5):205 -22.

15. DiMatteo MR. The role of effective communication with children and their families in fostering adherence to pediatric regimens. Patient Educ Couns 2004;55:339-44.

16. Unni EJ, Farrisb KB. Unintentional non-adherence and belief in medicines in older adults. Patient Educ Couns 2011;83:265-8.

17. Miller WR, Rollnick SP. Motivational Interviewing: Preparing People to Change Addictive Behavior. New York: The Guilford Press, 1991.
18. Miller WR, Rollnick SP. Motivational Interviewing: Preparing People for Change, 2nd edn. New York: The Guilford Press, 2002.

19. Stake RE. Case studies. In: Denzin NK, Lincoln YS, eds. Strategies of Qualitative Inquiry. Thousand Oaks: Sage, 1998:86-109.

20. Stake RE. The Art of Case Study Research. Thousand Oaks: Sage, 1995.

21. Stake RE. Multiple Case Study Analysis. New York: The Guilford Press, 2006.

22. Krueger RA, Casey MA. Focus Groups: A Practical Guide for Applied Research, 3rd edn. Thousand Oaks: Sage, 2000.

23. Seidman I. Interviewing as Qualitative Research: A Guide for Researchers in Education and the Social Sciences, 3rd edn. New York: Teachers College Press, 2006.

24. Patton MQ. Qualitative Research and Evaluation Methods, 3rd edn. Newbury Park: Sage, 2002.

25. Corbin JM, Strauss AL. Basics of Qualitative Research: Techniques and Procedures for Developing Grounded Theory, 3rd edn. Thousand Oaks: Sage, 2008.

26. Glaser BG. The constant comparative method of qualitative analysis. Soc Problems 1965;12:436-45.

27. Ely M, Anzul M, Friedman T, Garner D, Steinmetz AM. Doing Qualitative Research: Circles Within Circles. Philadelphia: Falmer, 1991.

28. Kieckhefer GM, Ratcliffe M. What parents of children with asthma tell us. J Pediatr Health Care 2000;14:22-126.

29. Mansour M, Lanphear B, DeWitt T. Barriers to asthma in urban children: Parent perspectives. Pediatrics 2000;106:512-9.

30. Committee on Quality of Health Care in America. Institute of Medicine. Crossing the quality chasm: A new health system for the 21st century. Washington: National Academies Press, 2001.

31. Tralongo P, Ferraù F, Borsellino N, et al. Cancer patient-centered home care: A new model for health care in oncology. Ther Clin Risk Manag 2011;7:387-92.

32. Wilson SR, Strub P, Buist AS, et al. Shared treatment decision making improves adherence and outcomes in poorly controlled asthma. Am J Respir Crit Care Med 2010;181:566-77.

33. Put $C$, van den Bergh $O$, Lemaigre V, Demedts M, Verleden G. Evaluation of an individualised asthma programme directed at behavioural change. Eur Respir Rev 2003;21:109-15.

34. Moullec G, Gour-Provencal G, Bacon SL, Campbell TS, Lavoie KL. Efficacy of interventions to improve adherence to inhaled corticosteroid medications in adult asthmatics: A systematic review and meta-analysis. Respir Med 2012;106:1211-25.

35. Juniper EF, O’Byrne PM, Guyatt GH, Ferrie PJ, King DR. Development and validation of a questionnaire to measure asthma control. Eur Respir Rev 1999;14:902-7. 


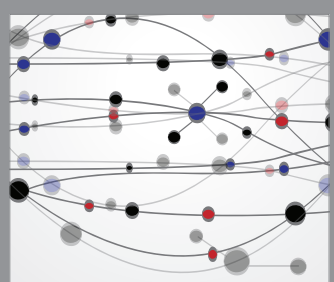

The Scientific World Journal
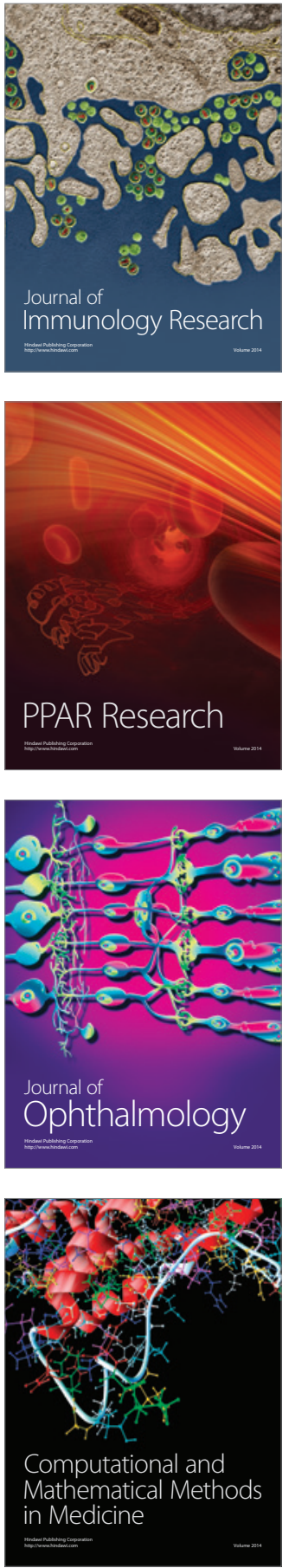

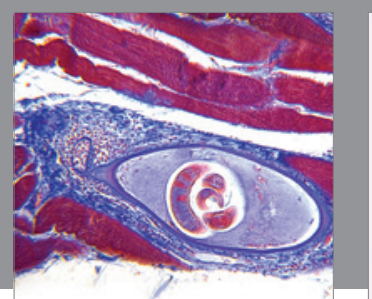

Gastroenterology Research and Practice

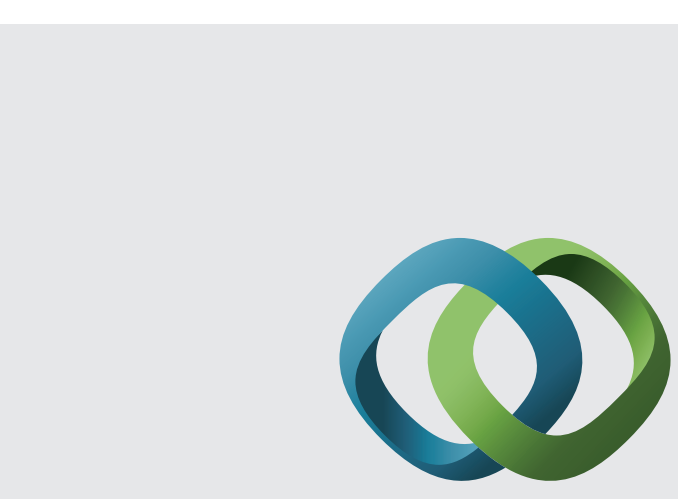

\section{Hindawi}

Submit your manuscripts at

http://www.hindawi.com
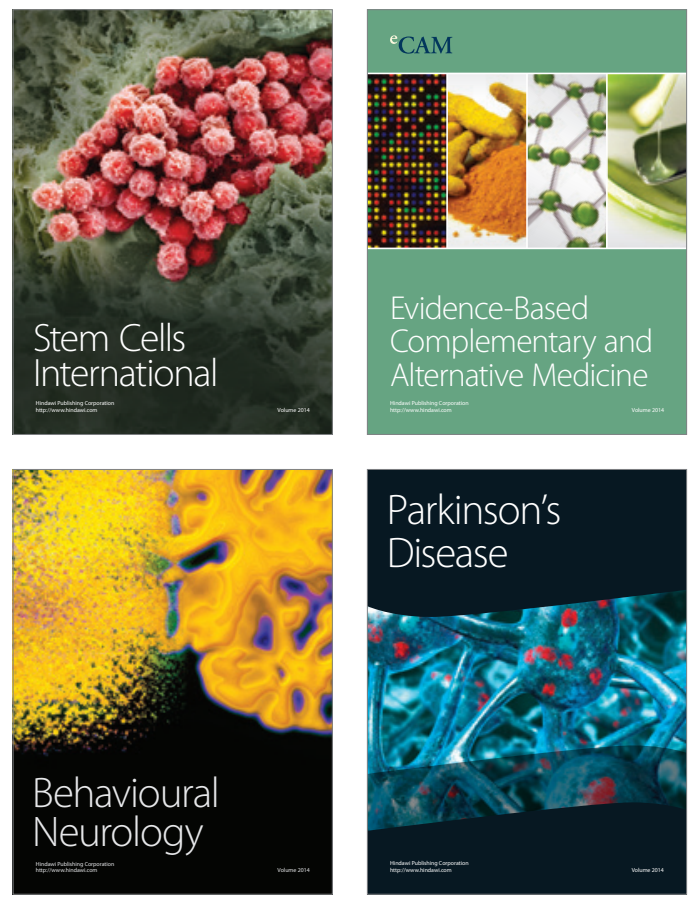
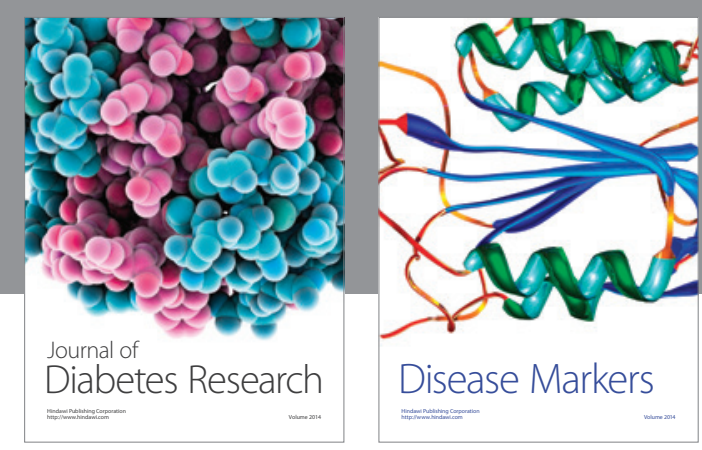

Disease Markers
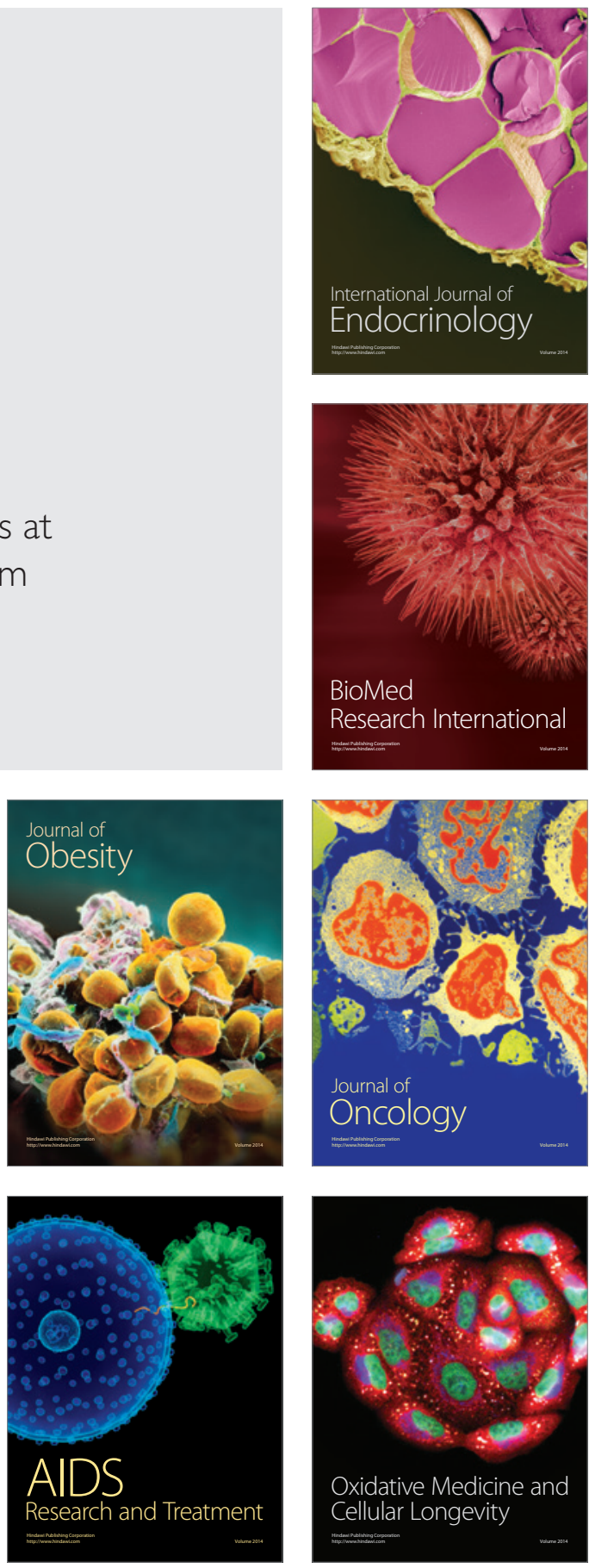